\title{
OUR EXPERIENCE IN THE TREATMENT OF LEPROSY WITH ETISUL:
}

\section{A Preliminary Report.}

By Prof. N. A. Torsuyev, V. V. Bogun, N. N. Torsuyeva, G. Ya. Chernyavskaya and V. V. Sokolov

In collaboration with Senior Doctor K. K. KhaRabadzhaKhov of the Rostov-on-Don Experimental-Clinical Leprosarium of the Russian Federation of Soviet Socialist Republics Ministry of Health; Senior Doctor L. N. Kasparov of the Upper Kuban Leprosarium; and Rector and Professor A. M. GANICHKIN of the Donets Medical Institute named after Gorkiy.

(From the original Russian text, translated by Mr. D. M. Blakeley in collaboration with Dr. J. Ross Innes.)

In spite of the high therapeutic effectiveness of sulphone compounds they cannot be considered ideal for the treatment of leprosy and a pressing search for new, effective preparations continues.

In view of the impossibility of experimentation on animals, new preparations for the treatment of leprosy usually come into use after the degree of therapeutic effectiveness has been established in relation to experimental tuberculosis, and sometimes after clinical tests.

E. Del Pianto (1950) was the first to report that a mixture of two mercaptans-mercaptobenzothiazol-5- oxygen sulphate and ethylthiosulphonate retards the development of tuberculosis in porpoises. Later (in 1959) he indicated that as early as 1948 he had drawn attention to the antitubercular properties of oxygen ethylthiosulphate in experiments with the Koch's bacillus in vitro.

G. BERTACCINI (1955) beginning his work at the end of 1954, was the first to check the effectiveness of ethylthiosulphonate on leprosy, and in 1957 reported interesting results from the treatment of 31 lepromatous type subjects with this substance over a period of nine months, prescribing doses of from 0.8 to $1.6 \mathrm{~g}$. every 24 hours.

J. G. Orbaneja, F. Contreras, M. Such, J. Gulllen, A. Garcia Perez, J. Tarabini, F. Moran and J. Terencio (1957) treated 34 lepromatous type subjects with the compound "Leprosan Aue-3" with definite clinical and bacterial improvements. Chemically this compound is poliaryl polysulphide, a wax-like substance with an exceptionally unpleasant smell, probably explained by the presence of several aryls of mercaptan. There is no smell however, in capsules, in fat or in fine powder form. This preparation is known as Leprosan (Aue EL-3).

G. W. Driver (1959, 1957), making a study, as from 1951, of 400 different derivatives of ethyl mercaptan, focussed his attention on 
diethyl dithiolizoftalene, a compound chemically very close to ethyl alcohol. This compound has the formula:

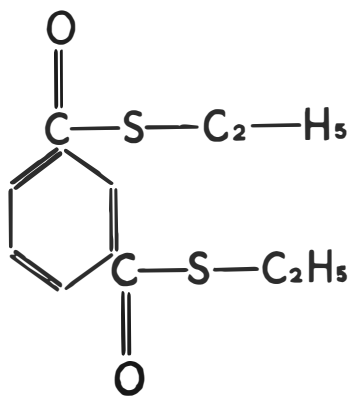

and is a light-yellow volatile oily liquid with a garlic smell. It was synthesized by the pharmaceutical division of the British firm Imperial Chemical Industries Ltd. and is sold under the trade name Etisul (synonyms: compound 15.688, ETIP, ET, Ditophal) in tubes, each containing $5.0 \mathrm{~g}$. of pure preparation mixed with $2.0 \mathrm{~g}$. of a neutral base (magnesium stereate). This preparation has the appearance and consistency of soft cream and should be kept in a cool place.

M. Naguib and J. M. Robson (1956) reported its high rate of efficacy; it retards the development of infection in mice infected in the eyes with the bacilli of rat leprosy. The mechanism of action of Etisul has not been explained. At present there is no chemical, biological nor clinical proof of its similarity in action, for example, to DDS or Ciba-1906, nor has its antagonistic influence on these preparations been established.

In experiments on tissue cultures G. E. DAVIES and G. W. DRIVER (1958) discovered that ethyl mercaptan affects the tuberculous bacilli to be found inside human monocytes and those of the porpoise. G. W. Driver (1960) confirmed the effectiveness of the preparation in relation to intracellular tuberculous bacilli even in the cultivation $10 \gamma / \mathrm{ml}$. He considers that the preparation modifies the exchange of monocytic substances, depriving the bacilli of substance essential for their activity. According to E. L. Rose (1958) ethyl mercaptan stimulates the natural defensive strength of the organism infected by the acid-fast mycobacteria and possibly strengthens the degree of antibacterial effectiveness of the macrophages.

T. F. Davey and L. M. Hogerzeil (1958) consider that the preparation does not act directly on the mycobacteria of leprosy, and T. F. DAveY (1959) thinks the mechanism of action more probably bacteriocidal rather than bacteriostatic.

Etisul is easily absorbed by the skin when rubbed in. J. S. LowE (1960) with the aid of C-14 tracer substances, established that Etisul is dissolved in the lipids of the skin and calculated that the concentration of mercaptan in the blood, which separates from Etisul after inunction, is $1.5 \mathrm{mg} . \%$, reaching a maximum on the second day. $\mathrm{He}$ 
also discovered the preparation in the liver. The transformation of Etisul into ethylmercaptan takes place slowly, by means of the skin esterase.

Using the 35-S tracer substance, D. G. Jamison and E. PALmer (1961) established that four hours after Etisul has been rubbed in particles of it are to be found in heavy concentration between the shaft of the hair and their outer root sheaths. It was also to be found in small quantities in the subepidermal region, a fact which shows the direct penetration of Etisul through the epidermis to the level of the hair follicles. After six hours radioactive particles were found in considerable quantities in the fatty cells and the connective tissue elements, forming an infiltrate. A concentration of radioactive particles is evidently always higher in those places where one can assume the existence of a great quantity of a large infiltration of cells. After 24 hours the marked particles penetrate into the circle of subepidermal nerve clusters and station themselves around the adventitial cells. The concentration of these particles increases around and inside the adventitial cells, in the granulomata, in the cells and lumina of the excretory sweat glands, this stage being particularly pronounced after 48 hours. Consequently Etisul is in fact secreted by the sweat glands, as M. LeChat pointed out (1959), and after 24 hours penetrates into the blood stream and is concentrated mainly in the sites of the pathological process.

The firm recommends that Etisul should be applied by inunction. Several minutes after application the patient is conscious of a garlic smell on his breath. He may then clean his teeth regularly with a peppermint-flavoured toothpaste or eat peppermint lozenges or sweets. Etisul is most conveniently applied in the bathroom in order to avoid soiling the patient's clothing.

The actual inunction of Etisul (one tube) is done briskly over the whole of the body, except for the arms and the stomach, the head and neck, and the hairy parts of the body. Fifteen minutes after application the patient takes a hot shower (not a bath). After thoroughly cleansing himself of Etisul with soap, the patient dries himself, puts on his day clothes and goes to the ward. Treatment is given to inpatients either by fellow patients undergoing the same treatment or by a nursing sister wearing thick rubber gloves. Before application the patient should be laid on a rubber sheet and afterwards the body wiped down with a sponge and washed with water. The washing of soiled clothing is not effective; the alkali of the soap joins with the Etisul to produce a sulphide smell. The firm, free of charge, provides a special substance, "Lissapol", for washing soiled clothing in boiling water.

The firm's instructions, enclosed in each container with the preparation, advise that inunction should last 15-20 minutes and that on its completion there should be a period of 15-20 minutes to air the 
skin before the patient dresses. Inunction should be carried out at any one time on a small part of the body. A. R. DAvison (1961) prescribed washing one hour after inunction; T. F. DAvEY and L. M. HOGERZEIL (1959) three hours after inunction.

Following T. F. Davey's advice, M. Lechat's patients (1959) were rubbed with Etisul only on the skin of the trunk, and treated each other. There followed a period of 2-3 hours after inunction and before washing during which the patients did not dress (these observations were made on the equator at Yonda leprosarium).

All the authors who have made a study of Etisul are unanimous in pointing out that it is well tolerated, also the absence of toxic complications whatever, even when the preparation is applied in doses of 5.0 g. every day (A. S. Garrett 1959). In systematic clinical analyses of urine and blood, it has been impossible to detect any abnormalities (T. F. Davey and L. M. HogerzeIL 1959).

According to the firm's prospectus, about $50 \%$ of patients during treatment with Etisul suffer slightly from erythema or dermatitis, but this quickly clears up when there is a temporary cessation in inunction. However, CoBURN and MARSDEN (1960) reported that in some cases dermatitis was prolonged because of skin allergy. The authors consider that in these cases treatment can be continued, if at the same time as the inunction a dusting of $1 \%$ of hydrocortisone is applied. An allergic dermatitis of this kind is mainly to be found in people whose skin is deficient in pigmentation. Dermatitis usually appears after seven to ten days and, if the infection is particularly severe, treatment has to be stopped, but in less severe cases it can be continued. After three applications of Etisul on one patient, $\mathbf{H}$. MCGREGOR (1961) observed that dermatitis, possibly allergic, was quickly developing but put this down not to Etisul treatment but to food which had contained a certain Saravakskiy plant from the Melanorrhoea group, of which the local name is "rengas".

Out of 86 patients receiving Etisul (inunctions two to five times a week) A. R. Davison (1961) observed six cases of dermatitis, which, in his opinion, were not connected with Etisul treatment but with the simultaneous dose of DDS; this is confirmed by two other cases of dermatitis (one severe, in the form of exfoliate erythrodermia), which developed in a control group of patients who had not received Etisul treatment.

C. M. Ross, J. F. Telfer and D. D. Hilton (1960) reported two cases of dermatitis, accompanied by an aggravation of specific eruptions, which quickly passed after Etisul inunctions had stopped. The authors emphasise, moreover, that amongst those patients who had taken DDS treatment rather badly the tolerance of sulphones became considerably better when Etisul was applied simultaneously; severe leprosy reactions ceased and the symptoms of erythema nodosum leprosum became markedly weaker. 
B. D. Molisworth (1961) reported that out of 29 patients treated with Etisul, dermatitis developed in one patient but quickly disappeared, although treatment was not stopped; apart from this, eruptions of mild erythema nodosum leprosum appeared only infrequently.

E. Del Pianto (1959) indicates that while Etisul is being given in combination with DDS, any existing leprosy reactions cease but usually reappear in weaker form after the course of inunction has finished. D. J. Jamison, E. Palmer and R. L. Vollum (1961), however, observed that children sometimes had leprosy reactions during combined treatment if the dose of Etisul were large. After a temporary cessation of inunctions, the reaction swiftly disappeared. Out of 133 patients treated with Etisul T. F. DaveY saw only two with weakly-marked leprosy reactions and M. LECHAT (1961) only two out of 28.

H. MCGregor (1961) observed that not a single case of severe nephritis developed during Etisul treatment. Out of 29 patients one, after 10 inunctions, developed severe erythema nodosum leprosum. By that time his bacterial index had fallen from 0.5 to 0.33 , but five months later, with the continuation of DDS treatment, the patient became bacterially negative.

According to A. R. DAvisON (1961), the percentage of people with erythema nodosum leprosum in a group treated solely with DDS was $37 \%$; in a group treated with DDS, Ciba- 1906 and Etisul twice a week it was $33 \%$ and amongst those treated with DDS, Ciba-1906 and Etisul five times a week it was $50 \%$.

Given the excellent tolerance of the preparation and the absence of unpleasant collateral effects, many authors think that Etisul could be widely used in outpatient treatment. (H. MCGregor 1961; C. M. Ross, J. F. Telfer and D. D. Hilton 1960; M. Lechat 1959 and others).

As far as the unpleasant garlic smell of Etisul is concerned, it is not very strong and is, in any case, less unpleasant than chaulmoogra preparations. According to M. LeCHAT (1959) and H. MCGREGOR (1961) the smell elicited complaints neither from other patients in the same wards not being treated with Etisul, nor from the patient's family in the case of outpatients. M. LECHAT (1959) points out that after each application the patient's perspiration acquires a definite smell of garlic. In the light of the above information it is a little surprising to see T. F. DAVEY's statement (1960) that because of the strong and unpleasant smell of ethyl mercaptan he was obliged to stop his first trials of Etisul on 18 patients.

Although CobUrn and MARSDEN (1960) consider that the Mycobacterium leprae does not develop resistance to Etisul, the majority of authors do not share their opinion.

T. F. DAVEY (1959), backed by very great experience in the use of 
Etisul, maintains that if treatment is given with Etisul alone its therapeutic effect ceases after 2-3 months. It is not yet clear if Etisul can again become effective after a break in treatment, during a second course. If Etisul treatment is begun at the same time as dosing with DDS the effect mentioned above is usually absent. On the other - hand, when a patient begins by taking DDS internally over a period of several weeks and Etisul treatment is then begun, in addition, when the daily dose has reached $200 \mathrm{mg}$., no resistance develops to the preparation by the end of the third month.

T. F. Davey and L. M. Hogerzeil (1959) maintain that without any doubt there is in fact resistance to Etisul from leprosy bacilli. The first indication of resistance is the recurrence of the typical Mycobacterium leprae in smears where only granular forms had appeared before. At the same time there is a definite increase in the activity of eruptions. This is usually to be observed three or four months after the beginning of treatment with Etisul alone. These developments are always absent if treatment is first begun with DDS, augmented with Etisul for about three months, and the treatment then continued with sulphone preparations.

A year later, T. F. DAVEY (1960) reported that out of 15 patients treated solely with Etisul, $6.0 \mathrm{~g}$. each, twice a week, there were signs of resistance in six. Such indications were completely absent from patients subjected to the combined treatment during seven months of observation.

In the beginning dosages and methods in the use of Etisul differed very widely.

Thus, E. Del Pianto prescribed for his 33 patients for one year ethyl sulphate daily, $1.2 \mathrm{~g}$. each, in one group and in combination with DDS in the other group. The preparations were taken six days a week; the daily dose was divided into three and taken three times a day, and it was found that the second method was the more effective.

T. F. Davey (1960) tried out several methods. One group of patients was treated solely with Etisul-6.0 g. each a week; five out of 15 lepromatous patients showed clinical improvement. In a group treated simultaneously with DDS and Etisul results were significantly better during the first 8-12 weeks than in the following three months. Etisul alone, applied over a period of three months, also gave good results.

However, the best results were achieved with patients who were first put on a course of DDS, orally, 100-400 mg. each, over a period of several weeks after which the treatment was augmented by Etisul inunctions. The author considers it most satisfactory to prescribe Etisul when the preliminary initial DDS treatment reaches its maximum dosage. H. McGregor (1961) treated 27 patients with Etisul over a period of 12 weeks and found clinical improvement in 
all of them. M. Lechat (1959) treated 28 patients, of whom 20 had previously taken DDS. They were all prescribed DDS orally in increasing doses, from 400 to $600 \mathrm{mg}$. each day, taken three times a day, and Etisul was rubbed in for 12-14 weeks, up to a dosage of $32.0 \mathrm{~g}$. for adults and about $15.0 \mathrm{~g}$. for children. All achieved good results, except two who left observation and two who had severe leprosy reactions.

A. R. Davison (1961) made a year's observation of 86 patients, divided into three groups: in the first ( 33 people) the patients took DDS orally and Ciba-1906; in the second (33 people)-DDS, Ciba-1906 and Etisul, 5.0 g. twice a week; and in the third group (20 people)-DDS, Ciba-1906 and Etisul, 5·0-6 g. once a week. In all groups there was a definite clinical improvement: the "lesion index" in group 1 fell from 6.6 to $4 \cdot 8$, in group 2 from $7 \cdot 1$ to 4.9 and in group 3 from $5 \cdot 9$ to $4 \cdot 5$.

T. F. Davey (1960) came to the conclusion that it was most sensible to use Etisul in conjunction with doses of DDS and, better still DDS and Ciba-1906 at the same time. Initially treatment should be given with DDS alone, and when the dose reaches $200 \mathrm{mg}$. should be augmented by Etisul; this combined treatment should continue for three months, after which sulphones should be used to carry on the treatment.

This principle is now generally accepted and even ICI Ltd. itself recommends users to observe it. At present it is becoming clear which method of treatment is the more advantageous; the 24-week one (application three times a week) or the twelve-week one (six times a week).

Only N. Muk eRJeE and S. Ghosh (1960) have been unsuccessful in using Etisul in isolation, in the treatment of 3 lepromatous patients over a period of six months; A. R. DAvison (1961) reported that the effectiveness of combined treatment was no greater than the usual treatment with sulphone preparations. Everyone else, however, affirms that this form of treatment is in fact more effective. True, T. F. Davey and L. M. Hogerzeil (1959) note that although in the majority of cases there is an exceptional clinical and bacteriological effect, this effect is very weak in some cases. In this connection, the writers remark, the nature of the patients' diet and the length of the illness may play a definite part.

Clinical improvement following treatment by ethylthiosulphate alone was observed by E. Del Pianto (1959) in two months; after 3-4 months with Etisul and DDS by T. F. DAVEY and L. M. HogerZEIL and in even in 3 weeks by H. MCGREGOR (1961).

T. F. DAvEY concludes (1959) that Etisul is "satisfactory" in the treatment of fresh cases of leprosy; in old cases, however, previously treated over a number of years with many other substances, for patients with few bacilli, the results obtained by Etisul treatment are 
not marked. M. LeChat (1959) describes the success of Etisul treatment as "exceptional", and in any case much greater than that achieved by sulphone treatment. In some cases he has been able to observe the disappearance of the leproma and the abundant lepromatous infiltrations literally in the space of two months.

According to $\mathrm{ICI}$ information, Etisul treatment obtains its best results, from a clinical and bacteriological point of view, in completely fresh lepromatous and dimorphous cases, which have previously not been treated at all.

D. J. Jamison, E. Palmer and R. L. Vollum (1961) consider an intensive combined course of treatment with Etisul and DDS to be the "optimum".

An improvement in the general condition and well-being of patients is noted by E. Del Pianto (1959), D. G. Jamison, E. Palmer and R. L. Vollum (1961), H. McGregor (1961) and many others.

C. M. Ross, J. F. Telfer and D. D. Hilton (1960), like other writers, point to the resolution of the lepromatous infiltrates and isolated leproma, the loosening of contractures, an easing of pain arising in thickened nerve trunks, and improvement in finger movement and also the comparatively swift disappearance of oedema in the dorsal surfaces of hands and feet. This last phenomenon is particularly emphasised by H. McGregor (1961). Apart from this, he draws attention to the exceptionally rapid resolution of leproma in several cases. D. G. Jamison, E. Palmer and R. L. Vollum (1961) write that in one case of severe lepromatous infection the disease had completely disappeared after three weeks of combined treatment with DDS and Etisul.

B. D. Molesworth (1961) relates that two of his patients were treated with DDS over five years and were constantly suffering from erythema nodosum leprosum eruptions and very severe nephritis. After Etisul began to be added to their treatment the trouble stopped and their bacterial index fell from 2.5 to 0.75 and from 2.1 to 1.3 . By the electrophetic method on paper, E. Del Pianto (1959) established that in patients with increased globulin content in the blood serum there was a rapid fall which went parallel with the clinical improvement.

E. Del Pianto (1959), in observations carried out over a period of one year on patients treated with Etisul alone, noted an improvement in the bacterial index, beginning as from the third month, and remarked that the typical bacilli disappear but that the granular forms of them remain.

According to M. LeCHAT (1959), even after two months the bacterial index falls considerably and several patients become negative, although clinically not all eruptions had then resolved.

T. F. DAVEY (1959) carried out observations on several groups of patients. In the first group patients received DDS orally and were also 
rubbed with Etisul, 3.0 g. each every two days, over a period of three months, and then took DDS; and even during the first 2-3 months there was an abrupt fall in the index. Under this method of treatment the index continued to improve even after nine months, which does not happen in the case of treatment by DDS alone. In the second group, over a long period of Etisul treatment (from three to 6 months), when the inunction was carried out in limited areas absorption was obviously inadequate and the index fell less than in the case of the patients of the first group. In all the patients of the third group, who had undergone a short course of Etisul treatment following chemotherapy by DDS orally, the bacilli became granular and in some cases disappeared altogether. The treatment of the fourth group was begun simultaneously with Etisul and DDS or Ciba-1906. During the first two months the fall in the bacterial index was more marked than in those patients treated with DDS alone, but in the fourth and fifth months the fall slowed down. In the first month of combined treatment of this kind the quantity of normal bacilli in five of the ten patients decreased by half. In scraped slitskin smears they had disappeared in nine patients, but in scrapings of the nasal mucus they were there as before. Some lepromatous patients were first given DDS orally (twice a week in doses of $100 \mathrm{mg}$., then of $200 \mathrm{mg}$, and finally of $300 \mathrm{mg}$.) after which treatment was augmented by Etisul. During the first two months the results were entirely satisfactory, but then there was a slowing down in the pace of the index fall. In the fifth group 15 patients with severe lepromatous leprosy, who had not previously been treated, received full doses of Ciba-1906 (2.0 g. each), DDS at the ordinary dosage and Etisul $(6.0 \mathrm{~g}$.) twice a week. After a month, in the case of 11 patients, the number of normal bacilli had decreased by half and by the end of the fourth month they had in all cases vanished completely in scraped slitskin incisions, but were to be found in the nose. The best bacteriological result was reached in this group.

T. F. DAVEY (1959) emphasises that signs of degeneration of Mycobacterium leprae, in the form of pronounced granularity, appear as early as three weeks after the beginning of Etisul treatment.

According to T. F. DAVEY (1959), in lepromatous patients, treated first with DDS and subsequently with Etisul, the bacterial index fell after eight weeks from 3.0 to 1.5 , whereas in the case of treatment with DDS alone it was three months before there was any bacterial improvement: Ciba-1906 has the greatest effect in the first three months but to a lesser extent than DDS and Etisul in combination. The best results occur in cases where the illness is recently contracted. There was no effect observed in old cases, previously treated over many years, cases with a great number of bacilli. Treatment with Etisul alone over a 2-3 month period is unsuccessful.

Six months after the initiation of combined treatment in several 
leprosaria, C. M. Ross, J. F. Telfer and D. D. Hilton (1960) observed a fall in the bacterial index in one group of patients from $1 \cdot 6$ to 0.6 , in a second from 2.0 to 0.8 and in a third from 3.5 to 0.8 . According to their observation, there are morphological changes in the bacilli in skin smears.

The bacilli from the lobe of the ear and the resolved lepromata disappear comparatively slowly. The best results in terms of bacterial negativisation are obtained by regular and combined treatment with DDS and Etisul.

T. F. DaveY (1960) again reported that there was a bacterial improvement in all 15 lepromatous patients treated by Etisul inunctions twice a week in $6.0 \mathrm{~g}$. doses. It is particularly noticeable that Etisul acts on leprosy bacilli of normal morphology; its influence is weaker on the granular forms.

In 29 lepromatous cases, treated initially over a nine-month period with DDS alone, the bacterial index fell from 1.8 to 0.83 ; and in the subsequent twelve days of combined treatment from 0.83 to 0.34 -a fall of $62 \%$.

According to B. D. MoleswORTH's observations (1961), out of 22 patients treated with Etisul and DDS, the average fall in the bacterial index was $40 \%$. Typical bacilli, which before treatment amounted to $90 \%$, disappeared during the first month and only reappeared periodically (over a 3-month period) in the cases of two patients and then disappeared again.

Thus, all the writers are in complete agreement in recording the rapid and beneficial effect of Etisul on the bacterial index. Unfortunately, this effect continues when Etisul is used alone for 3-4 months but weakens when combined treatment is employed.

Only A. R. Davison (1961), in a comparative study, was unable to record a noticeable difference. Thus, amongst his patients receiving combined DDS and Ciba-1906 treatment, the index fell during a period of one year's observation from 19.9 to $16 \cdot 2$ on average; DDS and Ciba-1906 treatment in conjunction with Etisul inunctions twice a week-from 21.8 to 18.3 ; similar treatment to above but with Etisul applications five times a week-from $20 \cdot 5$ to $16 \cdot 8$.

All writers agree that Etisul has a much stronger effect on normal leprosy bacilli and a much weaker one, if indeed it exists at all, on the granular forms. Carrying out treatment on four lepromatous patients, previously treated for 2-3 years with sulphones, W. H. JOPLING (1960) was unable to record any clinical bacterial improvement. He supposes that this is because of the absence in such patients of live normal staining bacilli; he assumes that their granular forms are already incapable of living.

There are very few data on the histological changes which take place under the influence of Etisul treatment. In most published work - as, for example, in T. F. DAvEY's article (1959) - there is the 
terse statement that after 3-4 months, together with a clinical improvement, "a histological improvement is also observed".

Only D. G. JAmison and E. PALmer (1960) have reported in greater detail: after Etisul treatment a comparatively rapid cellular change occurs (as early as after three weeks) and considerable decrease of infiltrate takes place in lesions of dimorphous leprosy, and particularly of perivascular infiltrate, and the bacilli gradually disappear; in tuberculoid cases the density of the infiltration diminishes, the number of epithelioid cells diminishes and the peripheral fibrosis is more marked; in lepromatous cases there is a sudden decrease in the density of the infiltrate, the gradual disappearance of bacilli in the infiltrate itself, but the bacilli remain in the nerve fibres of the skin.

Four months after the beginning of combined Etisul and DDS treatment, according to D. G. JAmison, E. PAlmer and R. L. Vollum (1961), the characteristic lepromatous infiltrate is replaced by a great quantity of fibroblasts, the number of bacilli diminishes and they take on a granular form.

The report of R. RHODES-JONES (1960) is worthy of great attention in connection with bacteriological research; if microscopic sections of skin for drying, stained according to Ziehl-Neelsen, are put in a thermostat at $37 \mathrm{deg}$. C. it is frequently impossible to observe the bacilli during subsequent days. In patients treated not with Etisul but with other preparations this phenomenon is absent. Checking his observations, the author established that the "disappearance" of the bacilli in such microscopic sections takes place in periods from 6 to 24 hours. He therefore recommends that stained microscopic sections from patients treated by Etisul should be looked over immediately after staining. It should be recalled that according to D. S. RIDLEY (1960) in ordinary preparations kept at room temperature the stained bacilli continue to be observable at least up to a period of six months. Recently ICI produced a new preparation-Etisul Formulation F-565-analogous to ordinary Etisul, but in liquid form. This preparation is cheaper, and is easier and quicker to apply and has less smell. In literature so far received by us there are two reports by S. G. BROWNE (1961): for three months he treated 17 lepromatous patients, at first giving them dapsone or thiambutosine (Ciba-1906) and then, in addition, EF-565 in doses of $5 \mathrm{ml}$. each twice a week in the form of inunction; he notes that the therapeutic effect of this substance is higher than that of Etisul. B. D. MolesWORTH (1961) records that it is well tolerated by the patient and that its therapeutic effect is an improvement in the clinical picture and a rapid fall in the bacterial index.

\section{Our Experience in Russia}

In the Upper Kuban leprosarium a course of Etisul treatment was 
begun on 10 patients; but of these one left the leprosarium after 10 days; the treatment of another was stopped after one week becauseof the development of universal toxic dermatitis from DDS; and, finally, the treatment of a third patient was curtailed because of an aggravation of chronic nephritis. Thus, seven patients ( 5 men and 2 women) underwent the full course of treatment. Their ages varied from 23 to 53. They were treated for three months, receiving DRT (sodium hydnocarpate) in the usual doses and Etisul applications six times a week. All patients were of the lepromatous type; four of them were in the progressive stage, two in the quiescent and one in the regressive stage of the disease. All except two had severe and widespread infection. Six patients, apart from skin lesions, had specific nephritis with contractures, atrophy of the hand muscles etc. The duration of the disease varied from three to 19 years (one patient three years; one 9 years; one 11 years; one 16 years; one 17 years; one 18 years; and one 19 years).

Only one patient had not previously been treated at all. The rest, over periods varying from one to six years, had been treated with various sulphone preparations (DDS, sulphetrone, sulphatin); the majority had had intradermal localised infiltrations of moogrol or other chaulmoogra preparations.

Mycobacterium leprae was present in scrapings of nasal mucus in two patients; in scraped slitskin smears from infected parts of the skin it was present in large quantities in five patients and in moderate quantities in two.

As a rule the treatment was well tolerated; there were no complications nor accompanying upsets. The following developments were recorded: an aggravation of neuritic pains during the first two weeks of treatment in two cases; a feeling of sickness, also during the first two weeks, in two cases; erythema nodosum leprosum in one case (before Etisul treatment the patient suffered from this repeatedly), erythematous spots on the chest (quickly disappeared) in one case and, again in one case, a mild papular itching rash on the skin of the stomach, which disappeared without trace after two weeks, in spite of continued treatment by inunction. As far as red and white corpuscles were concerned, there were no changes in haemoglobin content. In the case of three patients the erythrocyte sedimentation rate remained as before (within the range $5-10 \mathrm{~mm}$. an hour), in one case it rose from 8 to 15 and in the case of three patients it fell from $23-43 \mathrm{~mm}$. an hour to 3-8. The maximum arterial blood pressure in one patient fell from 150 to $105 \mathrm{~mm}$. of the mercury column; there were no changes in the rest. No pathological changes were to be observed in urine.

We have no grounds for connecting the development of universal toxic dermatitis in one patient with Etisul treatment. To judge from the clinical picture, it was most probably caused by sulphone preparations (DDS), with which the patient had previously been 
treated. The origin of the aggravation of chronic nephritis is not fully clear. In any case, as is mentioned above, special anti-leprosy treatment was temporarily stopped in both these cases.

In all patients treated with Etisul there was, to a greater or lesser degree, a marked clinical improvement and this comparatively rapidly (after 3-4 weeks) - certainly more rapid than in the case of treatment by any other preparation. By the end of the course of treatment all patients had shown good regression of the leproma and lepromatous infiltrates. Down hair, previously absent, appeared on the extremities in the-case of one patient. In a second case there was a noticeable loosening of contractures of the hands, and in a third an improvement in high-steppage gait.

Towards the end of the course of treatment, traces of Mycobacterium leprae, found in the two patients in scrapings of nose mucus, had completely disappeared and were not observable during the most thorough search. In one patient bacilli were completely absent in the serum from infected places on the skin; they remained in the case of six patients but in greatly reduced quantities, being granular in the majority of cases.

We determined the bacterial index according to the method suggested by M. E. Orlova. The index of homogenous forms of Mycobacterium leprae is recorded in the numerator and the granular forms in the denominator; the presence of amorphous fuchsinophil granularity is recorded by crosses. If the numerator diminishes regularly and progressively when the treatment is proceeding successfully, the denominator, proportionately with the disintegration of the bacilli, first increases and then diminishes too. The quantity of amorphous fuchsinophil dust, initially absent, gradually increases and then slowly begins to decrease.

The dynamics of the lowering of the bacterial index in individual patients can be judged from the following data:

\begin{tabular}{|c|c|c|c|c|c|}
\hline \multirow{2}{*}{ Patient No. 1} & $2 \cdot 0$ & $0 \cdot 2$ & $0 \cdot 17$ & & \\
\hline & $0 \cdot 07$ & $2 \cdot 2$ & $2 \cdot 3$ & & \\
\hline \multirow{2}{*}{ Patient No. 2} & $1 \cdot 2$ & $0 \cdot 3$ & 0 & $0 \cdot 3$ & \\
\hline & $1 \cdot 5$ & $0 \cdot 5$ & $0 \cdot 5$ & $0 \cdot 5$ & \\
\hline \multirow{2}{*}{ Patient No. 3} & $0 \cdot 25$ & 0 & 0 & & \\
\hline & 0.45 & 0.08 & 0 & & \\
\hline \multirow{2}{*}{ Patient No. 4} & $0 \cdot 17$ & 0 & $0 \cdot 5$ & 0 & 0 \\
\hline & $1 \cdot 2$ & $0 \cdot 5$ & $0 \cdot 5$ & 0.25 & 0 \\
\hline \multirow{2}{*}{ Patient No. 5} & $0 \cdot 7$ & $0 \cdot 5$ & 0 & $0 \cdot 2$ & \\
\hline & $0 \cdot 8$ & $0 \cdot 5$ & $0 \cdot 1$ & $0 \cdot 2$ & \\
\hline \multirow{2}{*}{ Patient No. 6} & $0 \cdot 3$ & $0 \cdot 5$ & $0 \cdot 17$ & 0.6 & \\
\hline & $0 \cdot 7$ & 0.9 & 0.6 & 0.6 & \\
\hline \multirow{2}{*}{ Patient No. 7} & 0 & $0 \cdot 5$ & $0 \cdot 3$ & $0 \cdot 5$ & \\
\hline & $0 \cdot 3$ & $0 \cdot 2$ & $0 \cdot 5$ & 0.5 & \\
\hline
\end{tabular}


In one patient (No. 6) the quantity of normal leprosy bacilli increased from $0 \cdot 3$ to $0 \cdot 6$, and in another (No. 7) the bacterial index of homogenous bacilli rose from 0 to 0.5 .

For these seven patients the average index decreased from 0.53 bef ore treatment to 0.21 by the end of the course, i.e. it was more than halved.

At the RSFSR Ministry of Health's experimental-clinical leprosarium at Rostov 10 lepromatous patients including three relapsed patients were given Etisul treatment. The age of these patients - six men and four women-ranged from 15 to 78: one was 15; two were between 31 and 40; two between 41 and 50; one between 51 and 60 ; two between 61 and 70 ; and two between 71 and 78. Duration of the disease varied in length from one to twenty years: four patients had had the disease for periods up to five years; one for a period between 6 and 10, and five for periods between 11 and 20 years.

Eight patients were in the progressive stage of the disease, one in the quiescent stage and one in the regressive. All patients, without exception, had previously received different sorts of leprosy treatment, mainly by sulphone preparations, intradermal injections of moogrol, and also Ciba-1906 over more or less lengthy periods of time. Before Etisul treatment Mycobacterium leprae was to be found in the case of all patients in scrapings of the nasal mucus and in the serum from skin lesions.

It can therefore be seen from the above that the group of patients receiving Etisul treatment consisted for the most part of severely affected patients with long case histories, half of whom were older than 50. This group of patients was treated by another method. The valid dose of Etisul $(5.0 \mathrm{~g}$.) was well rubbed into different parts of the integument, with the exception of hairy parts and the large flexures. After 40-60 minutes the patient took a hot shower and washed himself thoroughly using soap. The inunctions took place three times a week. The course of treatment lasted 24 weeks, during which time each patient rubbed in a total of $360.0 \mathrm{~g}$. of Etisul.

Simultaneously the patients were being treated with DDS according to the standard dosage (maximum dose $0 \cdot 1 \mathrm{~g}$. twice a day) and were also receiving vitamins, and iron preparations. During the course of treatment it was found necessary in two cases to replace DDS by intramuscular injections of a $50 \%$ aqueous solution of soluble sulphone (in saline) and in one case by Ciba-1906, in view of the low tolerance to 4,4, diaminodiphenyl sulphone; in two cases the course of Etisul treatment was not completed, being interrupted before time because of severe true leprosy reaction and eruptions of erythema nodosum leprosum, together with a bad general condition.

As a rule, Etisul was well tolerated by the patients. Only in three cases were there dyspeptic disturbances (loss of appetite, sickness, vomiting), together with weakness and indisposition. One of these 
patients, in addition, had a subfebrile temperature. The complete disappearance of these symptoms was achieved by the substitution for DDS of soluble saline sulphone injections with continued and uniıterrupted Etisul treatment. Before the course of Etisul treatment, one patient had constant albuminuria, sometimes reaching 0.33 albumen, together with white cells and, at times, slightly modified red cells. There was no worsening in the condition to be observed during the whole course of treatment.

One 40-year old patient suffering from a regressive, strongly marked lepromatous type of leprosy, after one month of combined treatment (DDS and Etisul) developed a severe leprosy reaction with lesions or nodes of the erythema nodosum leprosum type, fever reaching $38 \mathrm{deg}$. C. oedema of the hands and feet and bad general condition, leucocyte count reaching 23,450 , muffled heart tones, a lowering of haemoglobin to $39 \%$ ( $76 \%$ initially); the red cell sedimentation rate quickened from $33 \mathrm{~mm}$. per hour to $66-70 \mathrm{~mm}$. DDS and Etisul treatment was discontinued and replaced by anti-anaemic and desensitizing preparations. Although, in all probability, the leprosy reaction had nothing at all to do with the Etisul inunctions and was most probably caused by DDS, further treatment on this patient, who had received $180.0 \mathrm{~g}$.of Etisul, was stopped.

The second patient was 15 years old with severe lepromatous leprosy, had been ill for three years and continually had albumen in his urine (up to $0.66 \%$ ), erythrocytes and from time to time hyaline casts. He had continual eruptions of erythema nodosum leprosum and the lepromata became aggravated. He was not, therefore, treated regularly but with interruptions of varying length, and, having received $210.0 \mathrm{~g}$. of Etisul, was withdrawn from the tests. This was the only patient who did not derive some benefit from the combined treatment.

Only in the case of one patient -78 years of age-were Turk cells, $1: 200$ and 1:100, discovered, twice, in the blood, and these disappeared with continued treatment.

Only in the case of two patients, who did not finish the combined treatment because of leprosy reactions, did the erythrocyte sedimentation rate increase-from 33 to 51 and from 54 to $70 \mathrm{~mm}$. an hour. In all other cases it decreased to a greater or lesser but quite marked extent : from 52 to 43 , from 41 to 17 , from 50 to 35 , from 17 to 5 and from 39 to 16. In three cases the erythrocyte sedimentation rate did not change.

After 24 weeks of combined treatment the body weight of three patients had shown no change; one patient lost $2.5 \mathrm{~kg}$. in the middle of the treatment but then regained it. Four patients lost $1-4.5 \mathrm{~kg}$. and three gained weight in the range $3 \cdot 0-4 \cdot 5 \mathrm{~kg}$.

No transition from the Mitsuda negative reaction to positive was observed. It should be mentioned that in the case of one 49-year old patient with the progressive lepromatous type of the disease, the 
serological reactions (Kahn and Sachs-Witebsky) became negative two weeks after Etisul treatment had begun.

Except for the 15 year old patient mentioned above, who was withdrawn from treatment before the end of the course, all patients to a greater or lesser degree showed a very marked improvement clinically; spots disappeared, the lepromatous infiltrates resolved, and sometimes there was a complete modification of lepromata which became noticeably softer and flatter, some, the fresh ones particularly, resolving completely. Resolution of lepromata was sometimes observed in patients having a disease history of about 20 years. According to our observations, the lepromata and lepromatous infiltrates which yielded best to treatment were those in the upper part of the body and on the upper extremities, rather than those in the lower parts.

The combined treatment was particularly effective in the case of one 53 year old patient, suffering from very widespread and severe lepromatous type leprosy; apart from a very marked regression of infiltrates and lepromata on the integument, numerous lepromata had improved on the tongue and decreased in volume, and fibrous subcuticular lepromata on the dorsal surface of the hand, where they had formed a thick immovable conglomerate sharply decreased in number. There was a hardly noticeable lessening in the thickness of the massive infiltrate on the shins (chronic fibrous panniculitis). Mycobacterium leprae disappeared completely. In the case of another patient with a comparatively recent disease history, the skin was almost entirely cleared of lepromatous lesions and the bacilli in the skin serum disappeared entirely three months after the course of Etisul treatment had begun. It can be assumed that Etisul has a continuing eff ect for some time after the inunctions have come to an end.

After the end of the course of combined therapy, bacilli in the scrapings from the nasal mucus remained in only two patients (one of them did not finish the full treatment). After two weeks of Etisul treatment they had disappeared in the case of one patient; after one month in another; after 1.5-2 months in two others; after 2.5-3 in three cases and after 3.5 months in one case-data which, of course, show the very positive effect of Etisul.

The data presented are convincing proof of the therapeutic effectiveness of Etisul; in all cases, without exception, the index of the homogenous forms of the bacilli fell, sometimes very considerably, as for example in the case of Patient No. 8 from 3.42 to $0 \cdot 21$. The increase in the number of granular forms also proceeded regularly in all patients, reaching a maximum in the middle of the course of treatment, and had fallen in all cases without exception at the end of treatment, being lower than at the outset. The quantity of fuchsinophil dust in the large majority of cases had increased several times by the end of the course of treatment. A biopsy of infected 
parts of the skin was carried out on five patients both before Etisul treatment and at the end of the course. Histological study shows that under combined treatment by DDS and Etisul the lepromatous infiltrate resolves, and the contours of the lepracell become indistinct, while the quantity of bacilli decreases considerably at the expense of an increase in the granular forms and disintegration, and a transformation into fuchsinophil dust.

The dynamics of the bacterial index in the case of each separate patient can be judged from the following chart:

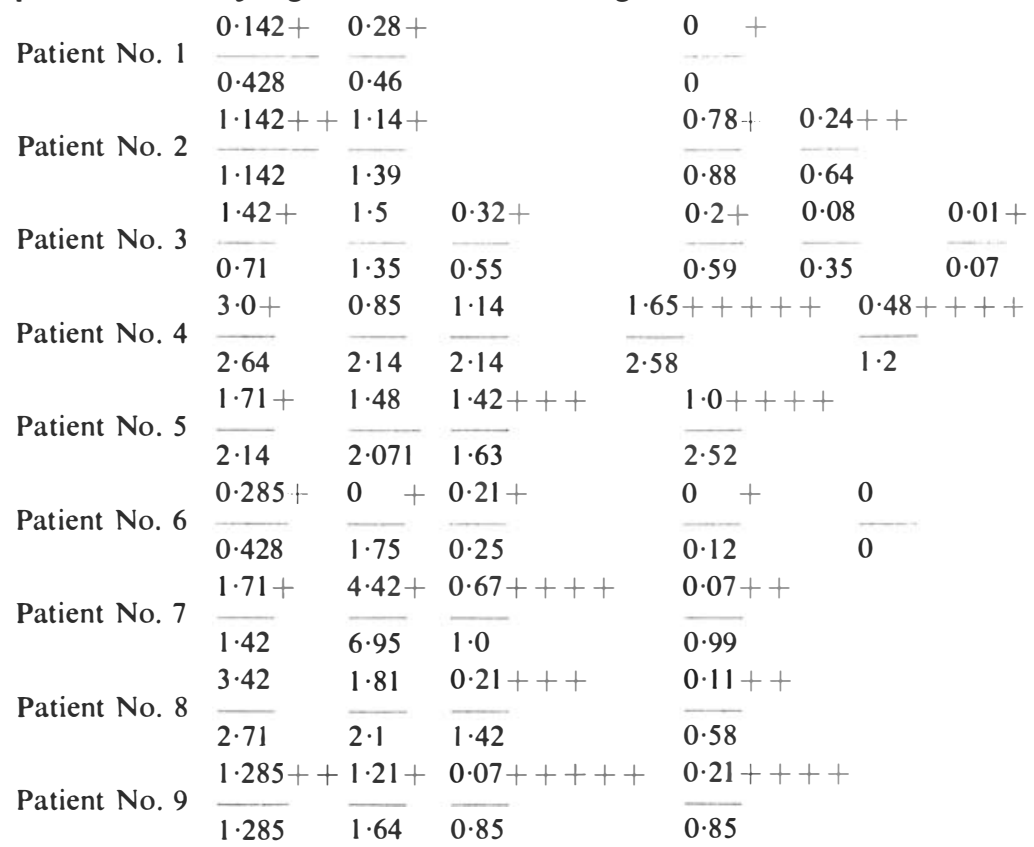

Patient No. 10 was not treated systematically and did not finish the course. In this group of patients there was not one single case of rise in the bacterial index of homogenous bacilli, and on average it fell by almost a third-from 1.568 to 0.606 .

The albumen fractions in the blood, which we determind by the paper electrophoretic method, it is not possible to record with definite regularities. At the end of the treatment the albumen content had increased in 8 patients and decreased in two: $\alpha 1$-globulin increased in 4 and decreased in 6, $\alpha 2$-globulin increased in 7 and decreased in 3; the content of $\gamma$-globulin increased in 3 and decreased in 7 patients.

On the basis of published data and our own material one may draw the following conclusions:

1. Etisul is an active, well tolerated, anti-leprosy substance and is a valuable addition to the arsenal of medicines for the treatment of lepromatous leprosy.

2. Its therapeutic effect is most clearly pronounced in patients with fresh manifestations of leprosy. 
3. Both methods of application (inunctions 3 times and 6 times a week) are equally effective.

4. The disappearance of bacilli in scrapings from the nasal mucus takes place considerably more quickly than in the infected parts of the skin.

5. Further study of the preparation is necessary, in particular to discover its effectiveness during repeated courses.

We tender our thanks to Dr. J. M. Mungavin (Medical Division, ICI Ltd.) who kindly made available to us the supply of the preparation necessary for-us to carry out our tests.

\section{References}

Bertaccini, G. L'etil-thiosolfato di sodio nella cura della lebra. Min. Dermatol. 1955, 32, 22.

Coburn, J. G. and Marsden, C. W. The Treatment of Cutaneous Tuberculosis with Diethyl-Dithiolisophthalate. Brit. J. Dermat. 1960, 72, 192.

Davison, A. R. A Clinical Evaluation of Etisul. Lep. Rev. 1961, 32, 40.

Davey, T. F. and HogerzeIl, L. M. Diethyl Dithiolisophthalate in the Treatment of Leprosy. Lep. Rev. 1959, 30, 61.

DAVEY, T. F. Diethyl Dithiolisophthalate in the Treatment of Leprosy. A Second Progress Report. Lep. Rev. 1959, 30, 141.

Davey, T. F. Some Recent Chemotherapeutic Work in Leprosy. Trans. Roy. Soc. Trop. Med. Hyg. 1960, 54, 199.

Davies, G. E. and Driver, G. W. Inhibitory Action of Ethyl Mercaptan on Intracellular Tubercle Bacilli. Nature 1958, 182, 664.

Davies, G. E. and Driver, G. W. The Antituberculous Activity of Ethyl Thiolesters, with Particular Reference to Diethyl Dithiolisophthalate. Brit.J. Dermatol. 1957, 12, 434.

Davies, G. E. and Driver, G. W. Action of Two Ethyl Thiol Esters against Experimental Tuberculosis in the Guinea-Pig. Brit. J. Pharmacol. 1960, 15, 122.

Garrett, A. S. Etisul Work in Progress in West and East Africa. Col. Res. Rep. $1958 / 59$, 1959, pp. 250-2.

Jamison, D. G., Palmer, E. and Vollum, R. L. Preliminary' Trial with Etisul in Northern Nigeria. Trans. Roy. Soc. Trop. Med. Hyg. 1961, 55, 142.

Jamison, D. G. and Palmer, E. The Distribution of ${ }^{35}$ S-labelled Etisul in the Skin as Indicated by Autoradiography. Lep. Rev. 1961, 32, 135.

Jopling, W. H. The Treatment of Leprosy. Postgrad. Med. J. 1960, 36, 634.

LECHAT, M. F. L'Utilisation pratique de l'Etisul (diethyl-dithiolisophthalate) pour le traitement de la lèpre chez l'Africain. Lep. Rev. 1960, 31, 265.

LowE, J. S. Metabolism of Compounds Related to Ethyl Mercaptan. Biochem. Pharmacol. 1960, 3, 163.

McGregor, H. A Preliminary Trial of Etisul in the Treatment of Leprosy Patients. Lep. Rev. 1961, 32, 36.

Molesworth, B. D. Preliminary Note on a Series of Cases of Lepromatous Leprosy Treated with Etisul. Lep. Rev. 1961, 32, 150.

Mukerjee, M., and Ghosh, S. Preliminary Trial of Etisul in the Treatment of Leprosy. Lep. Rev. 1960, 31, 275.

Naguib, M., and Robson, J. M. The Activity of Diethyl-dithiolisophthalate alone and Combined with Isoniazid in the Treatment of Murine Leprosy in the Mouse Cornea. Lancet $i, 1956,411$.

Orbaneja, J. G. et al. Primeros resultados del tratamiento de la lepra con un nuevo preparado: "Leprosan"'. Rev. Fontilles, Valencia, 1957, 4, 97.

DEL PIANTO, E. Chemotherapy of Tuberculosis with 2-mercapto benzthiazole and its Derivatives together with Salts of Sesters of Thiosulfuric Acid. Ricerca. Sc. 1950, 20, 83.

Del Pianto, E. The Thioethyl Compounds in the Therapy of Leprosy. Lep. Rev. 1959, 30, 23.

Rhodes-Jones, R. Preliminary Report on the Rapid Fading of M. Leprae in Sections from Patients Treated with Diethyl Dithiolisophthalate. Lep. Rev. 1960, 31, 200.

Rose, F. L. Ethyl Mercaptan-1 5,688. Pharm. J. 1958, 181, 235.

Ross, C. M., Telfer, J. F. and Hilton, D. D. An Account of the Use of Etisul in the Treatment of Leprosy in the Northern Region of Nigeria. Lep. Rev. 1960, 31, 260. 